NASA Technical Memorandum 103193

AIAA-90-2527

\title{
Xenon Ion Propulsion for Orbit Transfer
}

V.K. Rawlin, M.J. Patterson, and R.P. Gruber

Lewis Research Center

Cleveland, Ohio

Prepared for the

21st International Electric Propulsion Conference cosponsored by the AIAA, DGLR, and JSASS

Orlando, Florida, July 18-20, 1990

\section{N/SA}


Xenon Ion Propulsion for Orbit Transfer

by

V. K. Rawlin, M. J. Patterson, and R. P. Gruber

NASA Lewis Research Center

Cleveland, $\mathrm{OH}$

\begin{abstract}
$\underline{\text { ABSTRACT }}$
For more than 30 years, NASA has conducted an ion propulsion program which has resulted in several experimental space flight demonstrations and the development of many supporting technologies. Technologies appropriate for geosynchronous stationkeeping, Earth-orbit transfer missions, and interplanetary missions have been defined and evaluated. The status of critical ion propulsion system elements is reviewed in this paper. Electron bombardment ion thrusters for primary propulsion have evolved to operate on xenon in the 5-10 kW power range. Thruster efficiencies of 0.7 and specific impulse values of $4000 \mathrm{~s}$ have been documented. The baseline thruster currently under development by NASA LeRC includes ring-cusp magnetic field plasma containment and dished two-grid ion optics. Based on past experience and demonstrated simplifications, power processors for these thrusters should have approximately 500 parts, a mass of $40 \mathrm{~kg}$, and an efficiency near 0.94 . Thrust vector control, via individual thruster gimbals, is a mature technology. High pressure, gaseous xenon propellant storage and control schemes, using flight qualified hardware, result in propellant tankage fractions between 0.1 and 0.2 . In-space and ground integration testing has demonstrated that ion propulsion systems can be successfully integrated with their host spacecraft. Ion propulsion system technologies are mature and can significantly enhance and/or enable a variety of missions in the nation's space propulsion program.
\end{abstract}

\title{
INTRODUCTION
}

Electric Propulsion (EP) can offer major benefits for orbit transfer missions where fast delivery is not essential (such as in a launch on schedule environment). 1-4 For example, if a solar powered, ion based Electric Orbit Transfer Vehicle (EOTV) is used to perform a near-Earth orbit transfer from low-Earth orbit (LEO), $4700 \mathrm{~kg}$ is needed in LEO (payload + OTV). ${ }^{3}$ This compares to the $17,200 \mathrm{~kg}$ needed if an Inertial Upper State (IUS) is used. As illustrated in Figure 1 , these mass savings resulting from the higher performance of the electric upper stage allow a reduction in launch vehicle class (from Titan IV to Delta II). The trade-off is a longer transfer time from LEO to the operational orbit. For certain missions, the potential savings accruing from the use of an EOTV can exceed \$100M per launch. 3

Electrostatic ion thruster research in the United States is supported by the National Aeronautics and Space Administration's (NASA) Office of Aeronautics, Exploration and Technology (OAET) and is technically

Copyright (C) 1990 by the American Institute of Aeronautics and Astronautics, Inc. No copyright is asserted in the

United States under Title 17, U.S. Code. The U.S. Govern-

ment has a royalty-free license to exercise all rights under

the copyright claimed herein for Governmental purposes.

All other rights are reserved by the copyright owner. 
managed by NASA's Lewis Research Center (LeRC) and Jet Propulsion Laboratory (JPL). 5 Support is also provided by the United States Air Force (USAF), the Strategic Defense Initiative Organization (SDIO), and programs within several aerospace companies. Ion propulsion is also being developed in other countries for many applications, as summarized in the next section.

Elements comprising an ion propulsion system are shown in Table 1. Recent studies indicate that electric propulsion system elements are technically ready to be integrated into propulsion systems and flight demonstrated to enhance user acceptability. 1-4 To demonstrate this, the United States Air Force (USAF) is planning the Electric Insertion Transfer Experiment (ELITE). ${ }^{6}$ The initial ELITE program included the integration of $30 \mathrm{~kW}$ class ammonia arcjets and 5-10 kW class xenon ion thrusters, advanced photovoltaic solar arrays, an autonomous flight control system, and a diagnostics package. The ELITE propulsion system has recently been scaled back to a demonstration of $5 \mathrm{~kW}$-class arcjet technology. 7 However, for near-Earth missions, interest in solar powered propulsion subsystems with high performance, such as the ion propulsion subsystem, still exists. ${ }^{8}$ This paper discusses the status of critical elements of NASA's inert gas ion propulsion systems. While specific integration philosophies (such as selecting a modular or integrated propulsion system, power processing grounding strategies, and thermal impacts on the spacecraft) are extremely important, they are beyond the scope of this effort.

\section{BACKGROUND}

This section presents a brief historical overview of ion propulsion systems developed in the United States, Japan, West Germany, and Great Britain for space flight or pre-flight programs.

\section{United States}

NASA LeRC initiated its space electric propulsion program in 1957, which led to the development of the electron bombardment mercury ion thruster. 9 Figure 2 shows a cross section of a typical ion thruster. Gaseous propellant atoms are introduced into the discharge chamber where they are bombarded by electrons emitted by a hollow cathode and collected by the anode. The ionization process is enhanced by the presence of a magnetic field, the details of which will be discussed in a following section. Some of the electron-atom collisions result in the creation of ions which drift toward the accelerating electrodes, which are biased negatively with respect to plasma potential. These electrodes focus and accelerate the ions which exit the thruster in a broad beam. The ion beam is then neutralized by a stream of electrons emitted from an external hollow cathode called a neutralizer. Figure 3 traces the development of electron bombardment ion thruster technology at NASA from the $10 \mathrm{~cm}$ diameter device first laboratory tested in 1960.10 This concept was developed, integrated into a propulsion system, and tested on a 47 minute ballistic flight in the Space Electric Rocket Test I (SERT I). 11 The thruster test lasted 30 minutes and verified that the ion beam could be neutralized and that the thrust produced was nearly equal to that expected from ground test measurements and calculations. Laboratory thrusters, ranging in diameter from $5 \mathrm{~cm}$ to $150 \mathrm{~cm}$, have been fabricated and tested to verify scaling relationships. A $15 \mathrm{~cm}$ 
diameter thruster was developed for a second flight demonstration, designated SERT II.12,13 The SERT II system was launched into a sun synchronous $1000 \mathrm{~km}$ high polar orbit in 1970. The SERT II ion propulsion system contained all of the elements shown in Table 1. The extended operation of the two thrusters demonstrated long term spacecraft and propulsion system compatibility in the geocentric environment. 14 The thrust level was confirmed by several methods, including altitude changes and onboard accelerometer measurements. 12 An accelerating electrode erosion problem, not experienced in ground testing due to gravity effects, occurred during the flight test and this shortened the intended high voltage operating time. This problem was subsequently characterized and eliminated.15 The solar array for SERT II was the largest in space at that time and provided 1270 watts initially and about 800 watts after more than 11 years in space. In 1981, the propellant supply was exhausted and thruster experimentation was terminated.

In 1974, the sixth Advanced Technology Satellite (ATS-6) was launched into geosynchronous orbit. 16 While the two electron bombardment cesium ion engines failed due to propellant feed system problems, neutralizer operation was satisfactory and demonstrated control of the spacecraft potential as the spacecraft went in and out of eclipse or experienced magnetic substorms.

The success of the SERT II program led to the development of a propulsion system utilizing $8 \mathrm{~cm}$ diameter mercury ion thrusters sized for North-South stationkeeping (NSSK) functions of small communications satellites in geosynchronous orbit. The Ion Auxiliary Propulsion System (IAPS) 17 was integrated as an experiment on a proposed USAF spacecraft. The spacecraft is currently in storage and there are no plans to fly it. The flight test goa 1, after extended ground-testing 18,19, was to simulate a 7 year stationkeeping mission via demonstration of 7000 hours of full thrust operation with 2500 on/off cycles. The flight test was also intended to correlate the results of ground and space testing, especially in the areas of thruster effluents and system performance.

In addition to the auxiliary thruster program, the SERT II thruster was also scaled up in size and power for the performance of primary propuision functions. LeRC initiated the Solar Electric Propulsion System (SEPS) technology program in the early 1970 's. This program developed the $30 \mathrm{~cm}$ diameter, $2.7 \mathrm{~kW}$, mercury ion thruster, and other critical technologies required of a propulsion system. 20 The capabilities of SEPS enabled and/or enhanced a large class of planetary missions.21 The SEPS technology was transferred to NASA's Marshall Space Flight Center in 1980.9

Throughout the 1970's, mercury was the baseline propellant for ion thrusters. The major advantages of mercury are its high molecular weight, low ionization potential, storability, and convenient vaporization. These features initially offset toxicity, reactivity, and facility/spacecraft contamination issues. However, these considerations have more recently led to increased interest in inert gases for ion propulsion for large near-Earth space systems (LSS).22 Inert gases provide some performance benefits, such as nearly instantaneous startup and significantly simplified power processing, which positively impact orbit raising and stationkeeping functions. Inert gases are also noncontaminating and do not react with 
ground or space system elements, simplifying integration with the spacecraft and Earth-launch vehicles. They are also nontoxic and nonreactive when released to the biosphere, minimizing ecological concerns. Because of these considerations, the inert gases xenon, krypton, and argon were tested in the baseline mercury thruster developed for the SEPS program. 23 The thruster was operated up to $9 \mathrm{~kW}$, more than three times its rated power level of 2.7 $\mathrm{kW}$, and the ion current extraction capability was found to scale inversely, as expected, with the square root of the propellant atomic mass. Because of the similarities between xenon and mercury, the optimal operating conditions were found to be nearly identical to those with mercury. With the lighter gases, krypton and argon, the propellant efficiency decreased because the thruster had been optimized for mercury. The SEPS thruster, operated on xenon, became the baseline engine for primary ion propulsion.23,24 In addition to the efforts at LeRC, JPL simplified the SEPS ion propulsion sub-system 20 (BIMOD) and converted it to a two-thruster $10 \mathrm{~kW}$ xenon ion propulsion module. 24

A xenon ion propulsion subsystem (XIPS) has also been developed by Hughes Research Laboratories (HRL), 25 with INTELSAT support. This system was ground tested, with NASA support, for 4350 hours and 3850 ON-OFF cycles.26 This test simulated over 10 years of stationkeeping for a large communications satellite. The XIPS thruster is $25 \mathrm{~cm}$ in diameter and produces about $64 \mathrm{mN}$ of thrust. HRL has also designed a propulsion system with similar technology using a $13 \mathrm{~cm}$ diameter thruster. This version produces about $18 \mathrm{mN}$ of thrust. ${ }^{4}$

Japan

Cooperation between Japan's National Space Development Agency (NASDA), the National Aerospace Laboratory (NAL), and the Electrotechnical Laboratory (ETL) resulted in a successful space flight test of a small ( $2 \mathrm{mN}$ ) mercury ion propulsion system on the third Engineering Test Satellite (ETS-III). 27 Based on the results of that test and future mission trade-offs, NASDA has chosen to develop a xenon ion propulsion system for stationkeeping which utilizes $12 \mathrm{~cm}$ diameter, $23 \mathrm{mN}$ thrusters. 28

Development of this ion engine system (IES) is a joint effort by NASDA, Mitsubishi Electric Corporation (MELCO), and Toshiba. The IES is slated to perform the NSSK functions for ETS-VI, which is scheduled for launch in the early 1990's.29 Extensive testing of IES critical elements has been conducted with engineering model hardware at the component and subsystem levels.30 Japan is also developing a $30 \mathrm{~cm}$ diameter xenon ion thruster for auxiliary propulsion of LSS and for primary propulsion on an Orbit Transfer vehicle (OTV).

\section{West Germany}

The European Space Agency (ESA) has sponsored electric propulsion development programs for about two decades, resulting in xenon ion propulsion systems based on two different ionization processes. 31

The Radiofrequency Ion Thruster Assembly (RITA) will be tested as a flight experiment on the European Retrievable Carrier (EURECA-I), scheduled for launch in the early 1990's.32 RITA has also been proposed as one of two 
operational xenon ion systems for stationkeeping ESA's advanced communications technology satellite, SAT-2.33,34 RITA is comprised of flight level hardware utilizing a $10 \mathrm{~cm}$ diameter thruster (RIT-10) which uses radiofrequency (RF) energy to generate ions and then electrostatically accelerates these ions in the conventional manner. This thruster was initially developed for use with mercury propellant and was tested with mercury for 8000 hours. It has been converted to use xenon as the propellant and extended lifetests, to qualify it for the 10 year SAT-2 mission, are scheduled to begin this year. West Germany is also developing the RIT-35, a $35 \mathrm{~cm}$ diameter xenon ion engine for primary propulsion on planetary missions. 31

\section{Great Britain}

The UK-10 Ion Propulsion Subsystem (IPS) for SAT-2 has been designed and component development has begun. 34,35 IPS is based on the UK-10 electron bombardment xenon ion thruster, which evolved from the T5 mercury ion thruster. 36 Like the RITA thruster, the UK-10 has a beam diameter of $10 \mathrm{~cm}$. The UK-10 is an electron bombardment type thruster that utilizes a hollow cathode electron emitter to bombard propellant atoms and generate ions. T5 thruster components have been tested extensively with mercury and lifetesting with xenon is planned. 34 Currently, the program schedule is dependent on SAT-2's schedule. 35 A larger ion thruster (UK-25) for primary propulsion is also being developed in England. The UK-25 has a $25 \mathrm{~cm}$ beam diameter and has been operated on mercury and xenon. 31

In summary, a number of countries have developed, assembled, and tested complete flight qualified ion propulsion systems. Several have flown, some for extended periods, demonstrating the maturity of the technology.

Schreib's trilogy provides an excellent treatise concerning the timeliness and utility of xenon ion propulsion. $37-39$

\section{STATUS OF CRITICAL SYSTEM ELEMENTS}

The previous section referred to several ion propulsion systems which, with the exception of SEPS hardware, were primarily developed for stationkeeping applications. This section discusses the status of critical thrust system components and the characteristics of primary ion propulsion systems developed in the United States. In particular, the discussion considers ion thrusters, power processors, thrust vector control, and propellant storage and distribution. Component characteristics, such as thruster and power processor performance, power level, mass, and lifetime, as well as system particle and field effluents are also addressed. The power source, power distribution, thermal control, and structure are not considered.

\section{Thrusters}

As mentioned in the Background section, the SEPS thruster operated on xenon became the baseline engine for primary ion propulsion in the United States. Many of the missions studied under the SEPS program resulted in propulsion modules with 10 or more thrusters and power processors. System analyses indicate significant benefits in cost, specific mass, and simplicity can be obtained by increasing the thrust and power level of each thruster/power 
processor unit. Two approaches were taken to increase the engine thrust level. First, with $30 \mathrm{~cm}$ diameter thrusters, the beam current and voltage were increased. Total thruster power levels of up to $17 \mathrm{~kW}$ were demonstrated with no significant loss in thrust-to-power ratio. 40 Next, large $50 \mathrm{~cm}$ diameter thrusters were built and evaluated over similar power ranges.40-42 Two thruster magnetic field configurations were also evaluated and, as discussed below, one was selected on the basis of lifetime considerations.

Divergent magnetic field - Figure 4 shows a cross-section of the SEPS, or J-Series, xenon ion thruster tested at NASA LeRC and JPL in the low thrust primary propulsion programs.23,24 Notable features are the axial and radial rod-shaped permanent magnets used to generate a mildly divergent magnetic field between the cathode and screen grid pole pieces, and the use of a physical baffle between the cathode and anode to boost the discharge impedance and, therefore, the efficiency of ion generation.

After the performance of the J-Series xenon ion thruster was characterized, it was subjected to extended tests at the $10 \mathrm{~kW}$ input power leve 143 to verify solutions to known life-limiting mechanisms.44-48 During the development of the SEPS thruster, two major life-limiting mechanisms were identified. One was sputter erosion, by ions, of discharge chamber components, such as the cathode orifice plate, the discharge baffle, and the screen grid. The other was spalling of this sputtered material which was deposited at other discharge chamber locations. In general, the erosion rates of discharge chamber components were found to increase with increases in the discharge voltage and current, and beam current. Therefore, in order to offset anticipated increases of erosion rates in the $10 \mathrm{~kW}$ xenon thruster, the discharge voltage was reduced from 32 volts (SEPS condition) to 28 volts by reducing the discharge baffle diameter 23 as the beam current was increased from 2 to 5 amperes. Furthermore, the cathode orifice diameter was increased from $0.76 \mathrm{~mm}$ to $1.47 \mathrm{~mm}$ to avoid excessive orifice plate erosion expected at a cathode emission current of 32 amperes compared to 13 amperes for the SEPS thruster. With the exception of one area, the erosion rates of the known erodible discharge chamber components were successfully controlled through these cathode and baffle geometry improvements and adjusted operating conditions. However, the maximum erosion rate of the upstream side of the baffle increased from the $9 \times 10^{-9}$ $\mathrm{m} / \mathrm{hr}$ observed in SEPS tests 44 to between 660 and $900 \times 10^{-9} \mathrm{~m} / \mathrm{hr}$ during the $10 \mathrm{~kW}$ xenon tests. 43 This was clearly unacceptable because at this high rate, the baffle would be eroded completely through in less than 2000 hours. In addition, the life-limiting mechanism of spalling deposited sputtered material was exacerbated by the increased erosion rates observed with xenon. Elimination of the baffle and baffle mounting structure to avoid erosion and subsequent deposition of sputtered material resulted in severe performance degradation as the ion production cost nearly doubled. 40

The mechanism causing the observed baffle erosion was investigated with a retarding potential analyzer. 49 That effort detected energetic ions emanating from the hollow cathode plasma which required retarding potentials of over 50 volts to prevent their collection. Potentials of this magnitude were several times any electrode potential. Besides possessing energies sufficient to do sputter damage, the current density of these "jet" ions was found to increase dramatically with increasing cathode emission current. 
Research on baffle erosion in J-Series xenon ion thrusters has also been conducted at JPL. 50,51 Using highly polished sample baffle plates and a sensitive profilometer, this effort resulted in measurements of extremely high erosion rates of the upstream side of the baffle in short term tests of about 24 hours. It has been shown that some thruster internal erosion can be significantly reduced by adding small amounts of reactive gases, such as nitrogen, to the discharge chamber propellant.50-53 Using this technique, JPL reduced the upstream baffle erosion by factors of up to 18.5 under SEPS operating conditions. 51 However, such reductions are likely to be inadequate for high power thrusters, especially when redeposition is considered.

Because of the high erosion and subsequent redeposition rates observed with the J-Series divergent magnetic field thrusters, research on divergent field thrusters was terminated at LeRC.

Ring-cusp magnetic field - The magnetic field configuration of the present baseline 30 and $50 \mathrm{~cm}$ diameter thrusters is the ring-cusp design shown in Figure 2. Strong boundary magnetic fields for plasma containment eliminate the need for pole pieces or baffles near the cathode.

Thrusters with this geometry have been tested with mercury and inert gas propellants over a wide range of power levels and for periods of time up to 4350 hours $26,40,41,54-60$.

Performance - The performance characteristics of several two-grid, ring-cusp xenon ion thrusters are shown in Figures 5 and 6 . These data were taken from numerous studies. 41,58 , and 60 Figure 5 plots calculated thrust as a function of thruster input power for two-grid 25,30, and $50 \mathrm{~cm}$ diameter thrusters. The data show that the thrust increased nearly linearly from 0.07 to $0.5 \mathrm{~N}$ as the thruster input power was increased from 1.4 to $15 \mathrm{~kW}$. This trend was independent of thruster size. For the data shown, the thrust-to-power ratios varied from 0.046 to $0.032 \mathrm{~N} / \mathrm{kW}$, decreasing at the higher power levels, as discharge chamber conditions and grid voltages were varied over wide ranges. The thrust-to-power ratio is relatively insensitive to large variations in input power because the beam voltage is much greater than the ion production cost. In this case, the ratio varies nearly inversely with the square root of the beam voltage. For the data of Figure 5, the beam voltage was increased from about 900 to 2200 volts, explaining the approximately 30 percent decrease observed in the thrust-to-power ratio.

Figure 6 plots ion thruster efficiency, calculated from the data of Figure 5 , as a function of specific impulse. Thruster efficiency is given by:

$$
N_{T}=\frac{I_{S P} g}{2 P}
$$

Eq. 1

where $T$ is thrust in $N$, I $s p$ is specific impulse in $\mathrm{s}, \mathrm{g}$ is acceleration due to gravity $\left(9.81 \mathrm{~m} / \mathrm{s}^{2}\right)$, and $P$ is thruster input power in watts. The figure shows that thruster efficiency increased from about 0.5 to 0.8 as the 
specific impulse was increased from 2200 to $5000 \mathrm{~s}$. Equation 1 may be rewritten approximately as:

$$
N_{T} \simeq \frac{\gamma^{2} N u I_{s p}^{2}}{I_{s p}^{2}+\left(\frac{\gamma N u}{g}\right)^{2} \frac{2 e(E V)}{m}}
$$

Eq. 2

where $\gamma$ is a thrust loss factor accounting for beam ions which are multiply charged or have nonaxial trajectories. The term $\mathrm{Nu}$ is the measured propellant efficiency and is defined as ion beam current divided by propellant flow rate expressed as a current of singly charged ions. The e/m term is the charge-to-mass ratio for a xenon ion. The EV term is the ion production cost in watts per beam ampere. Equation 2 shows that thruster efficiency is approximately proportional to the square of the specific impulse divided by the sum of the square of the specific impulse and a nearly constant term related to the ion production cost. Thus, thruster efficiency would be expected to increase and approach a constant value (approximately the propellant efficiency) as the specific impulse term becomes large with respect to the ion production cost term. The data of Figure 6 show the increasing portion of this relationship.

Propellant type - Figures 5 and 6 also show the performance of the $30 \mathrm{~cm}$ diameter thruster 60 operated with krypton propellant. For a given power level the thrust obtained using krypton was lower than that with xenon, as expected, by approximately the square root of the atomic mass ratio. Thruster efficiencies comparable to those obtained with xenon are achievable, but at specific impulse values higher by the inverse of the square root of the atomic mass ratio, as indicated by Equation 2. It was also found that the discharge voltage required to reach the xenon efficiencies was much higher with krypton than with xenon (40 vs 27 volts). This would severely limit screen grid lifetime of the thruster with krypton propellant, just as it did in the J-Series thruster. 23 It is expected that a thruster redesign will be required to obtain krypton ion thruster lifetimes of interest.

Mass - A propulsion system mass mode 161 has been derived from a methodology previously presented.62 The model used the propulsion system components shown in Table 1. Estimates of the masses of advanced thrusters 62 nearly agree with the measured masses of the IAPS and SEPS thrusters. Ring-cusp thrusters built and tested 26,60 have masses of 12.7 and $12.5 \mathrm{~kg}$, respectively, also in close agreement with the model predictions.

Lifetime - SEPS, $30 \mathrm{~cm}$ diameter, mercury ion thrusters accumulated 30,000 hours of operation over a wide range of operating conditions. $45,46,52$ These experiences led to a relatively complete understanding of life-limiting mechanisms in $3 \mathrm{~kW}$ class ion thrusters. As mentioned earlier, this understanding was the basis for cathode and baffle geometry improvements and adjusted operating conditions. These alterations provided successful solutions to anticipated problems in an extended test of the 10 $\mathrm{kW}$ xenon J-Series thruster. 43 However, as discussed earlier, an increased current of energetic ions from the hollow cathode discharge caused unexpected and intolerable upstream erosion of the discharge baffle. Therefore, baffleless ring-cusp thrusters are now the baseline geometry. Two extended tests of baffleless ring-cusp ion thrusters have been conducted and are discussed below. 
A $1.3 \mathrm{~kW}$ ring-cusp xenon thruster, developed for NSSK applications, 25 was tested by HRL with xenon propellant in a cyclic mode for 4350 thrusting hours with 3850 on-off cycles. 26 The $25 \mathrm{~cm}$ diameter thruster used SEPS geometry cathodes and three-grid ion optics. During the first several hundred hours, three wear mechanisms were observed. The first was sputter erosion of the discharge cathode orifice plate. A new cathode with a larger diameter orifice $(1.27 \mathrm{~mm}$ compared to $0.76 \mathrm{~mm}$ for the original cathode), was tested for 3600 additional hours and showed no significant erosion. The second wear mechanism was elongation of edge apertures in the decelerator electrode. Apparently, beamlet divergence at the thruster perimeter, where the ion current density was much lower than at smaller radii, was large enough to cause direct decelerator electrode impingement. This erosion was minimized by reducing the diameter of the screen grid perimeter holes. The third wear mechanism observed was enlargement of accelerator grid apertures due to charge exchange ion impingement on the aperture walls. This caused long-term performance losses due to reduced propellant utilization efficiencies.

Low energy ions are formed when an electron transfers from a neutral propellant atom to an energetic beam ion. 63 When created away from the thruster these charge exchange ions are harmless to the thruster. When formed in the interelectrode space, the accelerator grid hole, or immediately downstream of the accelerator grid, however, these ions can fall back to the accelerator grid to cause sputter damage. With two-grid ion optics, most of this damage occurs on the downstream side of the accelerator grid. With three-grid optics, nearly all of the damage occurs on accelerator grid hole walls. 64 Erosion of accelerator grid apertures during a HRL wear mechanism test of the XIPS thruster led to a gradual reduction in beam current (about 4 percent per thousand hours). Approximately half of the erosion was attributed to neutral propellant and half to increased charge exchange ion production resulting from facility induced increases in the neutral density.

Figure 7 illustrates the effect of facility pressure.43,60 The facility pumping speed for xenon was briefly increased at constant thruster conditions by increasing the cryopumped surface area. This reduced the neutral density and facility induced charge exchange portion of the accelerator impingement current. The wear mechanism test demonstrated that inert gas thrusters tested in inadequately pumped facilities will experience significantly increased charge exchange ion erosion, which can substantially reduce and prevent accurate determination of accelerator grid lifetime.

A second extended test of a baffleless, ring-cusp thruster was conducted at LeRC and was recently terminated after accumulating 900 hours of continuous operation at an input power of $5.7 \mathrm{~kW} .60$ The thrust level was $0.2 \mathrm{~N}$. The thruster had a nominal diameter of $30 \mathrm{~cm}$ and employed two-grid ion optics. The ion beam voltage and current of 1500 volts and 3.2 amperes, respectively, were both approximately double those used in the HRL test. Like the $10 \mathrm{~kW} \mathrm{J-Series} \mathrm{xenon} \mathrm{ion} \mathrm{thruster} \mathrm{test} \mathrm{and} \mathrm{the} 1.3 \mathrm{~kW}$ XIPS test, no measurable screen grid erosion was observed in the recent LeRC test. Considering uncertainties in the measurement, the time to wear half way through the screen grid was estimated to be in excess of 30,000 hours.60 These results confirm that reducing the discharge voltage from 32 volts to 28 volts in high power xenon thrusters has effectively eliminated screen grid erosion as a thruster life-limiting mechanism. 
No measurable, irreversible thruster performance degradation was detected over the course of the LeRC $5 \mathrm{~kW}$ lifetest, other than that attributable to unoptimized neutralizer operation. 60 Accelerator grid apertures were found to be enlarged by an average of 2 percent (significantly below that observed in the HRL test26). Charge exchange ion erosion of the downstream side of the accelerator grid occurred around each accelerator grid hole. The accelerator grid was eroded entirely through at the charge exchange "pit" sites, from the center of the grid out to half radius. Both thruster and facility produced charge exchange ions are believed responsible. An estimated in-space erosion rate leads to an accelerator grid lifetime of about 11,500 hours.60 Pursuit of a complete understanding of the charge exchange ion production and sputtering processes, including the effects of facility pressure, is in progress. Extended test data acquired to date, however, still support the selection of two-grid optics as the baseline ion optics configuration for high power xenon ion thrusters.

\section{Power Processors}

An ion thruster requires a dedicated power processing unit (PPU). This PPU is the most massive (one to two times the propellant reservoir and thruster combined), and the most expensive ( 6 to 10 times as costly as the thruster) system component. 65 With state of the art electronic components, the PPU baseplate must be maintained over a narrow temperature range (typically $-20^{\circ} \mathrm{C}$ to $+50^{\circ} \mathrm{C}$ ) to ensure reliable operation and adequate performance.

This range must be maintained whether the PPU is off or on. When it is on, the baseplate must handle about 7 percent of the input power for contemporary higher power $(>1 \mathrm{~kW})$ thruster subsystems. The performance requirements and design of the PPU must, therefore, be carefully specified. Besides the usual need for high efficiency and low component mass, the impact of minimizing PPU parts count on subsystem cost, and reliability must be fully considered.

Performance - Efforts to simplify the PPU for mercury ion thruster systems began in the late 1970's.66-69 Many of the techniques developed have proven useful in xenon ion thruster power electronics. 25 Reduced thruster requirements, open-loop regulation techniques, and new integrated control circuits have all reduced PPU parts count and complexity.

The results of these simplifications are evident in the comparison of the IAPS, SERT II, SEPS, and XIPS PPU'S. Table II summarizes their characteristics together with estimates for both $5 \mathrm{~kW}$ and $10 \mathrm{~kW}$ xenon thruster PPU's. Input power level, power efficiency, specific mass, and parts count are compared.

Mass - PPU specific mass estimates for the $5 \mathrm{~kW}$ and $10 \mathrm{~kW}$ xenon systems were obtained from models.73 PPU specific masses are plotted in Figure 8 as a function of input power level. For the 5 and $10 \mathrm{~kW}$ PPU's listed in Table II, the power efficiency and parts count estimates are based on data for a 5 kW arcjet full-bridge breadboard power supply 74 and the XIPS breadboard power supply. 24

Design - The arcjet PPU is a valid reference for high power xenon PPU's because the beam supply for the latter can utilize the same basic 
architecture as that of the $5 \mathrm{~kW}$ arcjet supply. Only a single power stage of 5 or $10 \mathrm{~kW}$ is assumed in the Table II xenon system estimates. There may, however, be advantages to combining two or more power stages in order to reject waste heat over a wider area and, thereby, reduce maximum component temperatures.

Efforts are presently underway at NASA LeRC to determine an optimal control philosophy and to design, fabricate and test breadboard power electronics for 5-10 kW class laboratory xenon ion thrusters. It is expected that many of the previously reported power supply simplifications can be used. It is also anticipated that, for thruster control, simple analog schemes, such as those used in the SERT I 11 and SERT II 12 space tests, will prove superior to complex digital control. The initial designs of high power beam and discharge power electronics will be based on the successful $5 \mathrm{~kW}$ arcjet breadboard supply. 74 This same basic power circuit has been independently selected as a candidate for further development in other programs 75

For the first beam supply breadboard design, the output beam voltage will be proportional to solar array input voltage up to a maximum preset beam voltage. Closed-loop voltage regulation will occur when this predetermined beam voltage is reached. Both a beam current limit and recycle functions will be incorporated in the supply.

It may be advantageous, for certain missions, to extract maximum power from the solar arrays as the solar array power varies with array temperature, insolation and degradation. This feature can be accomplished in a stable mode when the beam supply is operating with beam voltage proportional to input solar array voltage. Beam current can be adjusted by closed loop-control of the discharge current until the maximum array power is attained. Implementation of this technique will require the addition of a control circuit comprising about 10 integrated circuits with associated components mounted on a sma 11 printed circuit card. 76 A potential drawback of this technique is that both the thrust and specific impulse will vary with the solar array power, since the beam voltage is proportional to the solar array voltage. These varying thruster parameters may complicate near-Earth mission planning, but can reduce the time spent at low altitudes. In addition, a solar array simulator will be necessary for testing. A similar maximum power tracking scheme was used in the skylab power system. 77

Lifetime - Over 111,000 hours of operation have been accumulated between SERT II, SEPS, IAPS, and XIPS breadboard (or higher leve1) power processors. Table III lists the longest and most significant tests, giving the thruster, the input power level, the PPU type or test location, the test time and environment, and a reference. TwO SERT II power processors were flown, performing without problems for more than 10 years. The long term reliability of PPU's is, therefore, well established.

The SERT II PPU's operated mercury ion thrusters with voltages as high as $+3000 \mathrm{v}$ and $-2000 \mathrm{v}$. The design of high power flight PPU's for inert gas ion thrusters is simpler and should be more reliable for near-Earth missions because: 1) no throttling is required; 2) fewer power outputs, hence, parts are necessary with the noncondensible inert gas propellant; 3 ) they 
incorporate improved power electronics; 4) they operate on higher solar array input voltages; 5) they will produce lower output voltages.

\section{Thrust Vector Control}

Thrust vector control (TVC) is required to accommodate initial offsets of the thrust vector due to assembly tolerances and to accomplish required thrust vector changes during a mission. These latter changes could be a result of variation in the number and location of operating thrusters, in the location of the spacecraft center of mass, or in attitude control requirements. TVC for ion thrusters has usually been accomplished with mechanical gimbals. The ATS 6 cesium thrusters employed accelerator grid displacement to achieve TVC by steering the ion beamlets from the screen grid holes through the accelerator grid. 16 This technique produced \pm 3 degrees of motion in each orthogonal axis.

The worst case initial grid alignment error for SERT II was estimated to be \pm 0.25 degrees. 13 The postulated total uncertainty (due to other reasons such as center of mass variations) in the thrust vector, however, was about 5 degrees. 13 The spacecraft gravity gradient restoring forces, which were used for primary spacecraft attitude control, allowed a maximum misalignment of the ful1 $28 \mathrm{mN}$ thrust vector of the thrusters at startup of 4.0 degrees in order to maintain attitude control. Therefore, each thruster was mounted on a conservatively designed gimbal to provide up to \pm 10 degrees of thrust vector correction in each of two orthogonal axes. The flight data indicated maximum thrust vector misalignments from all sources of 0.53 degree in the roll direction for one thruster and 0.24 degree in the pitch direction for the other thruster. ${ }^{13}$ Accurate yaw measurement were not obtainable. Because of the very small thrust vector misalignments, thrust vector corrections by the SERT II gimbals were never required during the primary phases of the experiment.

Table IV describes the mechanical thrust vector control systems built and demonstrated in thruster development programs to date and gives the maximum deflection angle each provides in two orthogonal axes. Masses of mechanical TVC assemblies for primary propulsion ion thrusters have been estimated to be the same as that built for SEPS, about 34 percent of the thruster mass.62 Figures 9 (a) and (b) are photographs of the SERT II and the SEPS gimbal systems, respectively. Mechanical thrust vector control is considered to be a mature technology for future mission planning.

Propellant Storage and Distribution

For SERT II, IAPS, and SEPS, liquid mercury propellant was stored in a spherical tank and flow to the thrusters was maintained by a passive nitrogen gas blowdown system. 17,20,78 The mercury propellant tankage fractions ranged from 0.13 for IAPS 17 to 0.02 for SEPS. 20

For most presently planned missions xenon propellant will be stored at high $\left(6 \times 10^{6}-29 \times 10^{6} \mathrm{~Pa}\right)$ pressures as a compressed gas.26,30,34,79-81 Liquid storage of inert gases at cryogenic temperatures has also been suggested, especially for argon.22 As a gas, xenon tankage fractions of 0.1 to 0.2 have been estimated. The methodology of reference 80 was used to calculate 
relative propellant tankage characteristics for xenon, krypton, and argon. It was found, as shown in Table $\mathrm{V}$, that at a storage pressure of $2.03 \times 10^{7}$ $\mathrm{Pa}$ (200 atmospheres) and a temperature of $21^{\circ} \mathrm{C}$, tankage fractions for krypton and argon are approximately 2 times and 5 times, respectively, greater than that needed for xenon. These increases mirror decreases in compressibility and density of the inert gases with decreasing atomic mass. 82 Using the tankage fractions given in Table $V$ for krypton and argon, relative to xenon, the mass of the EOTV described in reference 79 would increase by 5 or 17 percent if krypton or argon were used, respectively. Changes necessary to the tankage supporting structure for the lighter gases were not considered in these calculations. A propellant mass of $1041 \mathrm{~kg}$ would require spherical titanium alloy tanks of $0.49,0.62$, or $0.82 \mathrm{~m}$ diameter for xenon, krypton, or argon, respectively. Storage pressures other than 200 atmospheres may be optimal for the different gases and would yield somewhat different results.

Figure 10 shows one type of propellant storage and distribution system for xenon which has been proposed for stationkeeping 26 and OTV applications.79 It uses system elements which are mostly available as flight-qualified, commercial hardware. Two propellant tanks store xenon as a gas at high pressure. The propellant flow to the thrusters is controlled by redundant pressure regulators and flow impedances at the thruster, in an open-10op system. This propellant flow control approach has been demonstrated in extended tests of low power, cyclic 26 and high power, continuous 60 xenon ion thrusters.

Cryogenic storage of inert gas propellants has been considered.22 Such storage requires technologies similar to those developed for storage of liquid hydrogen and oxygen. It has been estimated that the ratio of propellant tankage mass to propellant mass, for argon, is about equal to the magnitude of the inverse of the cube root of the propellant mass in kilograms.22 Thus, for the example given above, the tankage fraction for cryogenic storage of $1041 \mathrm{~kg}$ of argon would be expected to be nearly 0.10 . cryogenic tankage fractions for krypton and xenon are reduced from that of argon by the ratios of the liquid densities. 62 Direct comparisons of propellant tankage mass fractions for different storage concepts would require specific detailed analyses and are beyond the scope of this paper.

\section{Ion Propulsion System Effluents}

Effluents from ion propulsion systems consist of particles and fields. 83 The emitted particles are both charged and uncharged. The charged particles consist of energetic beam ions and low energy ions and electrons, while the neutral particles are either propellant atoms or sputtered thruster

materials. The fields include static and dynamic magnetic fields and low to very high frequency electromagnetic fields. These particles and fields may interact with other spacecraft systems (such as solar arrays, structures, thermal control surfaces, and optical sensors) or spacecraft functions (such as communications, science, and spacecraft potential control). Table VI, taken from reference 83 , shows the potential interactions reviewed therein. That paper collated and summarized information from 76 reports describing analytical and experimental impact assessments obtained from ground and space tests. Since then, additional results from ground tests 18,84 and 
flight tests $27,85,86$ have become available. A recent survey 87 summarizes communications and electromagnetic interactions of ion and other types of electric propulsion systems with spacecraft, as observed in both flight and ground tests.

Six flights of ion thrusters or ion sources using mercury, cesium, or xenon propellants have generated sufficient detail to assess the impacts of the various ion thruster effluents on their host spacecraft.83,87 The results agreed, for the most part, with those of ground tests and verified models of the major effluent production and transport processes that have been identified.

The effects of the propellant selected for ion propulsion on spacecraft for deep space missions and on their scientific observations have been addressed.88 This overview of thruster/spacecraft interactions includes both experimental and analytical evaluations and seeks to assist in defining criteria, beyond propulsion system performance, for propellant selection.

In summary, no negative effects of ion propulsion system operation on spacecraft in suborbital, $1000 \mathrm{~km}$ polar orbital or geosynchronous flights have been observed when detailed preflight system integration tests have been conducted. This is understandable because, as compared with other types of propulsion, there is less particle efflux from low thrust, high specific impulse ion thrusters and nearly all of it is directly expelled in straight line trajectories. Ion propulsion also allows the use of benign propellants and provides the added benefit of spacecraft potential control. In addition, the large data base on ion thruster/spacecraft interactions, from both ground and space experiments, provides ion propulsion/spacecraft integration criteria.

\section{Conclusions}

For more than 30 years, NASA has conducted an ion propulsion program which has resulted in several experimental space flight demonstrations and the development of many supporting technologies. Technologies appropriate for geosynchronous stationkeeping, Earth orbit transfer missions, and interplanetary missions have been defined and evaluated. As a result of the ion propulsion program, unique and extensive in-house, industrial, and academic capabilities have been developed.

The status of several national ion propulsion programs and critical ion propulsion system elements was reviewed in this paper. Ion thrusters for primary propulsion have evolved in the United States over the past 30 years, and currently emphasis is on xenon and krypton ion thrusters which can operate from 5 to $10 \mathrm{~kW}$. Driven by lifetime considerations, the baseline thrusters presently under development by NASA LeRC include ring-cusp magnetic field plasma containment and dished, two-grid ion optics.

Ion thruster efficiency and specific impulse values are influenced by propellant atomic mass. With xenon, efficiencies greater than 0.7 at a specific impulse of 4000 seconds are attainable. With lighter krypton, thruster efficiency drops to 0.6 at similar values of specific impulse. When available data are scaled an efficiency of 0.7 is expected at a 
specific impulse of about 5000 seconds. Based on a recent 900 hour test at $5.7 \mathrm{~kW}$, xenon thruster lifetime is greater than 30,000 hours except for that of the accelerator grid which is strongly influenced by facility effects.

Power processors for mercury ion thrusters have demonstrated more than 100,000 hours of operation in ground tests and 6400 hours in space, intermittently over an eleven year period. Drawing on this long heritage and demonstrated simplifications, specific masses of power processing for 5-10 kW class inert gas ion thrusters will likely fall in the $7-4 \mathrm{~kg} / \mathrm{kW}$ range, respectively, with parts count on the order of 500, and power efficiencies near 0.94 . They should have a reliability comparable to those previously developed for mercury thrusters.

If required, thrust vector control may be readily implemented via individual thruster gimbaling. This is a mature technology with proven reliability. Inert gas propellants are generally stored as gases at high pressure but may be stored as liquids at cryogenic temperatures. In the gaseous form, propellant tankage fractions range from 0.1 to 0.2 for xenon and are higher by factors of about 2 and 5 for krypton and argon, respectively. Techniques for long-term cryogenic space storage of these gases require additional development but offer the promise of significantly lower propellant tankage fractions, especially as propellant quantities are increased.

Ion propulsion system interactions with spacecraft have been extensively investigated. In-space and ground integration testing has demonstrated that ion propulsion systems can be successfully integrated with their host spacecraft. Ion propulsion system technologies are mature and can significantly enhance and/or enable a variety of missions in the nation's space propulsion program. 


\section{References}

1. Sponable, J. M., and Penn, J. P.: "An Electric Orbital Transfer Vehicle for Delivery of NAVSTAR Satellites." AIAA Paper 87-0985, May 1987.

2. Deininger, W. D., and Vondra, R. J.: "Electric Propulsion for Constellation Deployment and Spacecraft Maneuvering." AIAA Paper 88-2833, July 1988.

3. Rosen, S, and Sloan, J.: "Electric Orbital Transfer Vehicle - A Military Prospective." AIAA 89-2496, July 1989.

4. Beattie, J. R., and Penn, J. P.: "Electric Propulsion - A National Capability." AIAA 89-2490, July 1989.

5. Stone, J. R., and Bennett, G. L.: "The NASA Low Thrust Propulsion Program." AIAA 89-2492, July 1989.

6. Schmidt, W., Sanks, T., and Andrews, J. C.: "The Astronautics Laboratory of the Air Force Systems AFAL." AIAA 89-2494, July 1989.

7. Andrews, J., and Sanks T.: "Arcjet Propulsion for ELITE." AIAA 90-2526, Paper proposed for the 21st IEPC, July 1990.

8. Space Systems Division: "Operational Solar Electric Orbital Transfer Vehicle Study." Sol. PRDA No. 90-12. Commerce Business Daily, Issue No. PSA-0059, March 2, 1990, p. 2.

9. NASA LeRC Staff: "A Case History of Technology Transfer." NASA TM 82618 , August 1981 .

10. Kaufman, Harold R.: "An Ion Rocket with an Electron-Bombardment Ion Source." NASA TN D-585, 1961.

11. Cybulski, R. J., et al: "Results from SERT I Ion Rocket Flight Test." NASA TN D-2718, 1965.

12. Kerslake, W. R., Goldman, R. G., and Nieberding W. C.: "SERT II-Mission Thruster Performance and In-Flight Thrust Measurements." Journal of Spacecraft and Rockets, Vol. 8, No. 3, March 1971, pp. 213-224.

13. Rulis, R. J.: "Design Considerations and Requirements for Integrating an Electric Propulsion System into the SERT II and Future Spacecraft." AIAA Paper 70-1123, August 1970.

14. Kerslake, W. R.: "SERT II Thrusters - Still Ticking After Eleven Years." AIAA Paper 81-1539, 1981.

15. Bechte1, R. T.: "Effect of Neutralizer Position on Accelerator Wear for a 30 Centimeter Diameter Ion Bombardment Thruster." NASA TM $\mathrm{X}-67926,1971$. 
16. 01sen, R. C.: "Experiments in Charge Control at Geosynchronous Orbit-ATS-5 and ATS-6." Journal of Spacecraft and Rockets, Vol. 22, May-June 1985, pp. 254-264.

17. Dulgeroff, C. R., et a 1: "Ion Thruster System $(8 \mathrm{~cm})$ Cyclic Endurance Test." NASA CR 174745, Hughes Research Laboratories, October 1984.

18. Power, J. L.: "Ground Correlation Investigation of Thruster/Spacecraft Interactions to be Measured on the IAPS Flight Test." IEPC Paper 84-39, May 1984 (NASA TM 83598).

19. Francisco D. R., Low, C. A., Jr., Power, J. L.: "Successful Completion of a Cyclic Ground Test of a Mercury Ion Auxiliary Propulsion System," IEPC Paper 88-035, October 1988.

20. "30-Centimeter Ion Thrust Subsystem Design Manua1." NASA TM-79191, 1979 .

21. Jones, R. M., Sauer, C. G.: "Advanced Solar Electric Propulsion (ASEP) for Planetary Missions." IEPC 84-47 17th International Electric Propulsion Conference, May 1984.

22. Byers, D. C., and Rawlin, V. K.: "Critical Elements of Electron-Bombardment Propulsion for Large Space Systems." Journal of Spacecraft and Rockets, Vol. 14, November 1977, pp. 648-654.

23. Rawlin, V. K.: "Operation of the J-Series Thruster Using Inert Gas." AIAA paper 82-1929, November 1982.

24. Aston, G., Brophy, J. R., Garner, C. E., and Pless, L. C.: "Operating Characteristics of a 10-kW Ion Propulsion Module." AIAA Paper 87-1006, May 1987.

25. Beattie, J. R., et a1: "Xenon Ion Propulsion System." AIAA Paper 85-2012, September 1985.

26. Beattie, J. R., Matossian, J. N., and Robson, R. R., "Status of Xenon Ion Propulsion Technology." AIAA Paper 87-1003, May 1987.

27. Kitamura, S., et a 1: "ETS-III Ion Engine Flight Operations in the Extended Mission Period." Journal of Propulsion and Power, Vol. 2, No. 6,1986 .

28. Shimada, S., et a 1: "20 mN Class Xenon Ion Thruster for ETS-VI." AIAA Paper 87-1029, May 1987.

29. Kuriki, K., and Nakamura, Y.: "Electric Propulsion Projects and Researches in Japan." IEPC Paper 88-003, October 1988.

30. Shimada, S., et a 1: "Ion Engine System Development of ETS-VI," AIAA Paper 89-2267, July 1989.

31. Berry, W., Bartoli, C. and Trippi, A.: "The ESA Policy and Programme for the Development of Electric Propulsion." IEPC Paper 88-001, October 1988. 
32. Bassner, H., Bartoli, C., and Trippi, A.: "Status of the

RITA-Experiment on EURECA." IEPC Paper 88-029, October 1988.

33. Bassner, H., Berg, H., and Kukies, R.: "The Design of RITA Electric Propulsion System for SAT 2." IEPC Proposed Paper 90-2539, July 1990.

34. Fearn, D. G.: "The Proposed Demonstration of the UK-10 Ion Propulsion System on ESA's SAT-2 Spacecraft." IEPC Paper 88-031, October 1988.

35. Smith, P.: "Design and Development of the UK-10 Ion Propulsion Subsystem." IEPC Paper 88-033, October 1988.

36. Fearn, D. G., and Hughes, R. C.: "The T5 $10 \mathrm{~cm}$ Mercury Ion Thruster System." AIAA Paper 78-650, 1978.

37. Schreib, R.: "Planning for Ion Propulsion on Communication Sate11ites." AIAA Paper 84-42, 17th IEPC, 1984.

38. Schreib, R.: "Utility of Xenon Ion Stationkeeping." AIAA Paper 86-1849, June 1986.

39. Schreib, R.: "Readiness Appraisal: Ion Propulsion for Communication Sate1lites." AIAA Paper 88-0777, March 1988.

40. Patterson, M. J., and Rawlin, V. K.: "Performance of 10-kW Class Xenon Ion Thrusters." AIAA Paper 88-2914, Ju1y 1988.

41. Rawlin, V. K.: "Performance of Large Area Xenon Ion Thrusters for Orbit Transfer Missions." NASA TM 102049, May 1989.

42. Rawlin, V. K., and Millis, M. G.: "Ion Optics for High Power 50cm-diam. Ion Thrusters." AIAA Paper 89-2717, July 1989.

43. Rawlin, V. K.: "Internal Erosion Rates of a $10 \mathrm{~kW}$ Xenon Ion Thruster." AIAA Paper 88-2912, July 1988.

44. James, E. L., and Bechte1, R. T.: "Results of the Mission Profile Life Test First Test Segment: Thruster J1." AIAA Paper 81-0716, Apri1 1981.

45. Collett, C. "Thruster Endurance Test." Hughes Research Labs, Malibu, CA, May 1976, NASA CR 135011.

46. Bechte1, R. T., Trump G. E., and James, E. L.: "Results of the Mission Profile Life Test." AIAA Paper 82-1905, November 1982.

47. Power, J. L.: "Solutions for Discharge Chamber Sputtering and Anode Deposit Spalling in Small Ion Thrusters." AIAA paper 75-399, New Orleans, LA, 1975.

48. Collett, C. R. and Bechtel, R. T.: "An Endurance Test of a 900 Series 30-cm Engineering Mode1 Ion Thruster." AIAA Paper 76-1020, November 1976. 
49. Friedly, V. J., and Wilbur, P. J.: "High Current Hollow Cathode Phenomena." AIAA Proposed Paper 90-2587, July 1990.

50. Garner, C. E., Brophy, J. R., and Aston, G.: "The Effects of Gas Mixtures on Ion Engine Erosion and Performance." AIAA Paper 87-1080, May 1987.

51. Garner, C. E., and Pless, L. C.: "Techniques for Reducing Spalling and Increased Operating Life of Xenon Ion Engines." AIAA Paper 89-2714, July 1989.

52. Rawlin, V. K., and Mantenieks, M. A.: "Effect of Facility Background Gases on Internal Erosion of the $30 \mathrm{~cm} \mathrm{Hg}$ Ion Thruster." AIAA Paper 78-665, April 1978.

53. Wilbur, P. J.: "A Model for Nitrogen Chemisorption in Ion Thrusters." AIAA Paper No. 79-2062, 1979.

54. Sovey, J. S.: "Improved Ion Containment Using a Ring-Cusp Ion Thruster." Journal of Spacecraft and Rockets, Vo1. 21, No. 5, September-october 1984, pp. 488-495.

55. Beattie, J. R., and Poesche1, R. L.: "Ring-Cusp Ion Thrusters." IEPC Paper 84-71, May 1984.

56. Patterson, M. J.: "Performance Characteristics of Ring-Cusp Thrusters with Xenon Propellant." AIAA Paper 86-1392, June 1986.

57. Yamagiwa, Y., et a 1: "A $30 \mathrm{~cm}$ Diameter Xenon Ion Thruster - Design and Initial Test Results." IEPC Paper 88-095, October 1988.

58. Beattie, J., and Matossian, J.: "High-Power Xenon Ion Thrusters." AIAA Proposed Paper 90-2540.

59. Kitamura, S., Miyazaki, K., and Hayakawa, Y.: "1000 Hour Test of $14 \mathrm{~cm}$ Diameter Ring-Cusp Xenon Ion Thruster." AIAA Proposed Paper 90-2542.

60. Patterson, M., and Verhey, T.: "5 kW Xenon Ion Thruster Lifetest." AIAA Proposed Paper 90-2543.

61. Galecki, D. L., and Patterson, M. J.: "Nuclear Powered Mars Cargo Transport Mission Utilizing Advanced Ion Propulsion." AIAA Paper 87-1903, June 1987.

62. Byers, D. C., Terdan, F. F., and Myers, I. T.: "Primary Electric Propulsion for Future Space Missions." AIAA Paper 79-0881, May 1979.

63. Staggs, J. F., Gula, W. P., and Kerslake, W. R.: "Distribution of Neutral Atoms and Charge-Exchange Ions Downstream of an Ion Thruster." Journal of Spacecraft and Rockets, Vol. 5, No. 2, February 1968, pp. $159-164$. 
64. Meadows, G. A.: "Development of a Self-Shielding Small Hole Accel Grid Ion-Extraction System." AIAA/DGLR Paper No. 78-692, San Diego, CA, April 1978.

65. Robson, R. R.: "Advances in Series Resonant Inverter Technology and Its Effect on Spacecraft Employing Electric Propulsion." AIAA 82-1881, November 1981.

66. Rawlin, V. K.: "Reduced Power Processor Requirements for the $30 \mathrm{~cm}$ Diameter Hg Ion Thruster." AIAA 79-2081, October 1979.

67. Wessel, F. J., and Hancock, D. J.: "Simplified Power Processing for Ion-Thruster Subsystems." AIAA 83-1394, June 1983.

68. Gruber, R. P.: "Simplified Power Supplies for Ion Thrusters." Journal of Spacecraft and Rockets, Vol. 19, September-October 1982, pp. $\overline{451-458 .}$

69. Gruber, R. P.: "Simplification of Power Electronics for Ion Thruster Neutralizers," Journal of Spacecraft and Rockets, Vol. 21, September-October 1984, pp. 473-480.

70. Bagwe11, J. W.: "Review of SERT II Power Conditioning." Journal of Spacecraft and Rockets, Vol. 8, No. 3, March 1971, pp. 225-230.

71. Wessel, F. J., Hancock, D. J., Dulgeroff, C. R., and Williamson, W. S.: "8-cm Ion Thruster Characterization: Supplementary Final Report, NASA CR 180819, October 1987.

72. Low, C.: Private Communication, NASA Lewis Research Center, May 1990.

73. Patterson, M. J., and Curran, F. M.: "Electric Propulsion Options for 10 kW Class Earth Space Missions." NASA TM 102337, May 1989.

74. Gruber, R., Gott R., and Haag, T.: "5 kW Arcjet Power Electronics." AIAA Paper 89-2725, July 1989.

75. Forsyth, A., Evans, P., and A7-Mothafar, M: "A Comparison of D.C. to D.C. Converter Topologies for High Power Ion Engine Control." AIAA $89-2270$, July 1989.

76. Gruber, R. P.: "Solar Array Maximum Power Tracking with Closed-Loop Control of a 30-Centimeter Ion Thruster." NASA TMX-73643, March 1977.

77. Gruber, R. P.: "High Efficiency Solar Cell Array Peak Power Tracker and Battery Charger." IEEE PCSC Record, April 1970.

78. Zavesky, R. J., and Hurst, E. B., "Mechanical Design of SERT II Thruster System." NASA TM X-2518, 1972.

79. Herme 1, J., et al: "Modular, Ion-Propelled, Orbit Transfer Vehicle." Journal of Spacecraft and Rockets, Vol. 25, No. 5, September-October 1988, pp. 368-374. 
80. Burkhart, J. A., and Seikel, G. R.: "Feasibility Studies on an Auxiliary Propulsion System Using MPD Thrusters." AIAA Paper 71-695, June 1971.

81 Berg, H., and Bassner, H.: "Propellant Storage and Feed System for the Radio Frequency Ion Propulsion Assembly RITA." AIAA Proposed Paper 90-2592, July 1990.

82. Cook, G. A.: "Argon, Helium, and the Rare Gases." Vol.1 Interscience, NY, 1961, p. 241.

83. Byers, D. C: "Electron Bombardment Thruster Field and Particle Interfaces." Journal of Spacecraft and Rockets, Vol. 16, No. 5, September-October 1979, pp. 289-301.

84. Carruth, M. R., Jr. ed: "Experimental and Analytical Evaluation of Ion Thruster/Spacecraft Interactions." Jet Propulsion Lab Pasadena, CA, Pub. 80-92, January 1981 (a1so NASA CR-163975).

85. Kitamura, S.: "Development of the Engineering Test Satellite-3 (ETS-3) Ion Engine System." Translation NASA TM-77538, 1984.

86. Masek, T. D., and Cohen. H. A.: "Satellite Positive-Ion-Beam System." Journal of Spacecraft and Rockets, Vol. 15, January-February 1978, pp. $27-33$.

87. Sovey, J. S., Carney, L. M., and Knowles, S. C.: "Electromagnetic Emission Experiences Using Electric Propulsion Systems." Journal of Propulsion and Power, Vo1.5, No. 5, September-October 1989, pp. 534-547.

88. Martin, A. R.. and Latham, P. M.: "Propellant Selection Criteria for Deep Space Electrically Propelled Missions." IEPC Paper 88-096. October 1988. 


\begin{tabular}{l} 
THRUST MODULE \\
THRUSTERS \\
POWER PROCESSORS (PPU) \\
PPU THERMAL CONTROL \\
THRUST VECTOR CONTROL \\
THRUSTER STRUCTURE \\
PROPELLANT DISTRIBUTION \\
\multicolumn{1}{c|}{ INTERFACE MODULE } \\
PROPELLANT \\
PROPELLANT TANKAGE \\
INTERFACE MODULE STRUCTURE \\
POWER MANAGEMENT AND THRUST SYSTEM \\
CONTROL
\end{tabular}

\section{TABLE II - POWER PROCESSOR CHARACTERISTICS}

\begin{tabular}{|l|l|l|c|c|c|c|}
\hline POWER PROCESSOR & SERT II & SEPS & \multicolumn{1}{|l|}{ IAPS } & \multicolumn{1}{|l|}{ XIPS } & \multicolumn{2}{|c|}{ PROJECTED } \\
\hline PROPELLANT & MERCURY & MERCURY & MERCURY & XENON & \multicolumn{2}{|c|}{ XENON } \\
\hline $\begin{array}{l}\text { INPUT POWER } \\
\text { LEVEL, kW }\end{array}$ & 0.98 & 3.05 & 0.17 & 1.3 & 5 & 10 \\
\hline $\begin{array}{l}\text { POWER EFFICIENCY, } \\
\text { PERCENT }\end{array}$ & 87 & 87 & 75 & 92 & 94 & 94 \\
\hline $\begin{array}{l}\text { SPECIFIC MASS, } \\
\text { kg/kW }\end{array}$ & 16.9 & 12.3 & 66 & 7.9 & 6.6 & 4.1 \\
\hline $\begin{array}{l}\text { APPROXIMATE } \\
\text { PARTS COUNT }\end{array}$ & 1100 & 4000 & 1700 & 400 & 500 & 550 \\
\hline REFERENCE & 66,70 & 20 & 71,72 & 25 & -- & - \\
\hline DEVELOPMENT YEARS & LATE '60'S & MID '70'S & MID '70'S & MID ' 80 'S & \multicolumn{1}{|c|}{ EARLY' 90 'S } \\
\hline
\end{tabular}


TABLE III - ACCUMULATED POWER PROCESSOR TEST HOURS

\begin{tabular}{|l|l|r|r|c|}
\hline \multirow{2}{*}{ THRUSTER } & PPU/TEST LOCATION & \multicolumn{2}{|c|}{ TEST TIME, HBS } & \multirow{2}{*}{ REFERENCES } \\
\cline { 3 - 4 } & & AIR & VACUUM & \\
\hline \multirow{2}{*}{ SERT II } & LERC & 1000 & 2400 & 13 \\
& TRW & & 6900 & 12 \\
(.98kW) & MCDONNELL & & 8000 & 12 \\
& POLAR ORBIT \#1 & & 3800 & 14 \\
& POLAR ORBIT \#2 & & 2600 & 14 \\
\hline IAPS & HRL & & 10,300 & 17 \\
(.17kW) & LERC & 3600 & & 19 \\
\hline SEPS & HRL CONSOLE & 15,000 & & 45,48 \\
& TRW 2 INVERTER BB & 10,000 & 100 & -- \\
(3.05kW) & TRW 3 INVERTER BB & 17,300 & -- & 46,52 \\
& ENG. PROTOTYPE (EP) & 6750 & 690 & 46 \\
& FUNCTIONAL MODEL, FM1 & 3260 & 3120 & 46 \\
& FM 2 & 1190 & 170 & 46 \\
& FM 3 & 3170 & 160 & 46 \\
& FM 4 & 7540 & 0 & 46 \\
\hline \multirow{2}{*}{ XIPS } & & & & \\
(1.4kW) & HRL . & 4350 & -- & 26 \\
\hline
\end{tabular}

TABLE IV - MECHANICAL THRUST VECTOR CONTROL DESIGNS

\begin{tabular}{|c|c|c|c|c|}
\hline \multirow[t]{2}{*}{ PROGRAM } & \multirow[t]{2}{*}{ GEOMETRY } & \multirow[t]{2}{*}{ MOTION } & \multicolumn{2}{|c|}{ MASSES, KG } \\
\hline & & & THBUSTER & GIMBAL \\
\hline SERT II & $\begin{array}{l}\text { TWO CONCENTRIC RINGS, } \\
\text { FOUR BEARINGS, } \\
\text { TWO LINEAR ACTUATORS } \\
\text { \{SEE FIG. 9a\} }\end{array}$ & $\begin{array}{l} \pm 10^{\circ} \\
\text { EACH } \\
\text { AXIS }\end{array}$ & 3.0 & $7.7^{*}$ \\
\hline IAPS & $\begin{array}{l}\text { CROSS PIN } \\
\text { HINGE, } \\
\text { TWO LINEAR } \\
\text { ACTUATORS }\end{array}$ & $\begin{array}{l} \pm 10^{\circ} \\
\text { EACH } \\
\text { AXIS }\end{array}$ & 2.0 & 1.6 \\
\hline SEPS & $\begin{array}{l}\text { CROSS PIN } \\
\text { HINGE, } \\
\text { TWO LINEAR } \\
\text { ACTUATORS\{SEE FIG 9b\} }\end{array}$ & $\begin{array}{l} \pm 40^{\circ} \text { ONE } \\
\text { AXIS } \\
\pm 15^{\circ} \text { ONE } \\
\text { AXIS }\end{array}$ & 8.9 & 3.4 \\
\hline
\end{tabular}

- INCLUDES INTEGRAL THRUSTER AND PROPELLANT TANK SUPPORT STRUCTURE 
TABLE V - RELATIVE TANKAGE PROPERTIES OF INERT GASES

\begin{tabular}{|l|c|c|}
\hline GAS* & $\begin{array}{c}\text { TANKAGE MASS } \\
\text { FRACTION }\end{array}$ & $\begin{array}{c}\text { TANK RADIUS FOR } \\
\text { 1041 } \mathrm{kg}, \mathrm{m}\end{array}$ \\
\hline XENON & 0.14 & 0.49 \\
KRYPTON & 0.27 & 0.62 \\
ARGON & 0.75 & 0.82 \\
\hline
\end{tabular}

* gas stored at $2.03 \times 10^{7} \mathrm{~Pa}(200 \mathrm{ATM}), 21^{\circ} \mathrm{C}$

TABLE VI - POTENTIAL INTERACTION AREAS PRESENTED IN LITERATURE (REF. 83)

\begin{tabular}{|c|c|c|c|c|c|}
\hline \multirow{2}{*}{$\begin{array}{l}\text { SPACECRAFT SUBSYSTEM } \\
\text { OR FUNCTION }\end{array}$} & \multicolumn{5}{|c|}{ ION SYSTEM PARTICLE AND FIELD EFFLUX } \\
\hline & $\begin{array}{l}\text { NONPROPELLANT } \\
\text { PARTICLES }\end{array}$ & $\begin{array}{l}\text { NEUTRAL } \\
\text { PROPELLANT }\end{array}$ & $\begin{array}{l}\text { ION } \\
\text { BEAM }\end{array}$ & $\begin{array}{l}\text { LOW } \\
\text { ENERGY } \\
\text { PLASMA }\end{array}$ & FIELDS \\
\hline SOLAR ARRAYS & • & • & • & - & \\
\hline THERMAL CONTROL & - & • & - & - & \\
\hline OPTICAL SENSORS & • & • & • & • & • \\
\hline COMMUNICATIONS & • & • & • & • & • \\
\hline SCIENCE & • & • & - & - & - \\
\hline $\begin{array}{l}\text { STRUCTURES AND } \\
\text { MATERIALS }\end{array}$ & & • & - & - & \\
\hline POTENTIAL CONTROL & & & - & - & \\
\hline
\end{tabular}




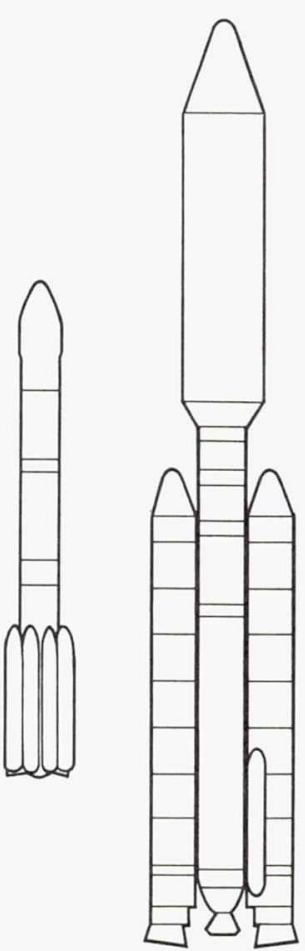

ELECTRIC CHEMICAL

MASS AT LEO, Kg

TRIP TIME, DAYS

LAUNCHER

OTV

ESTIMATED COST, MS
4700

180

DELTA II

SEPS

124
17200

TITAN IV

IUS

250

FIGURE 1. - IMPACTS OF ADVANCED ORBIT TRANSFER PROPULSION (REF. 3).

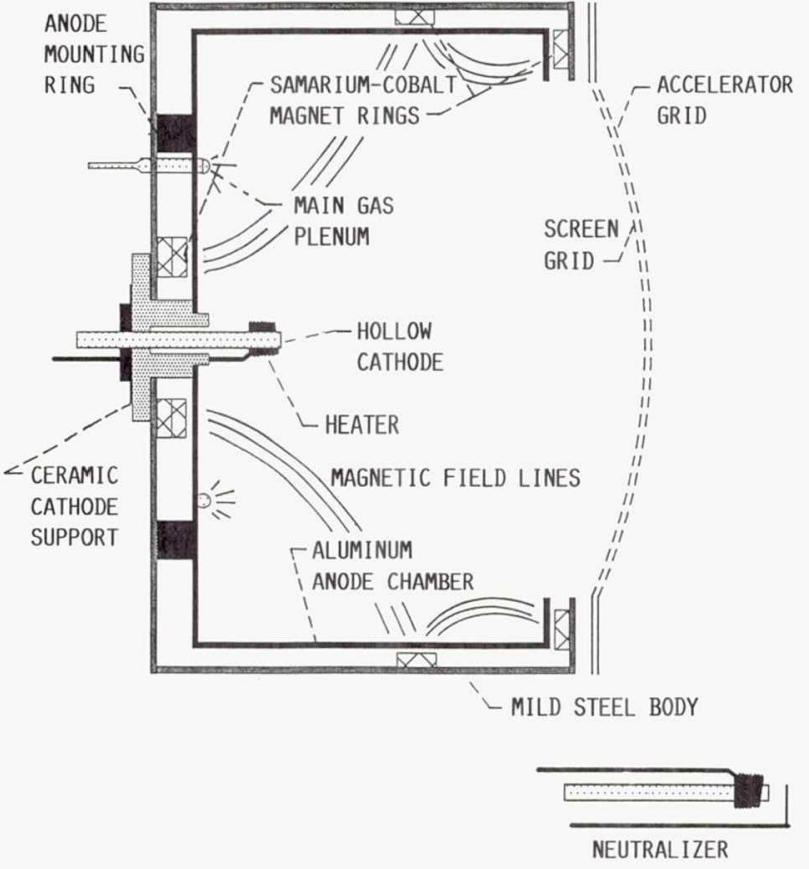

FIGURE 2. - TYPICAL RING-CUSP ION THRUSTER.

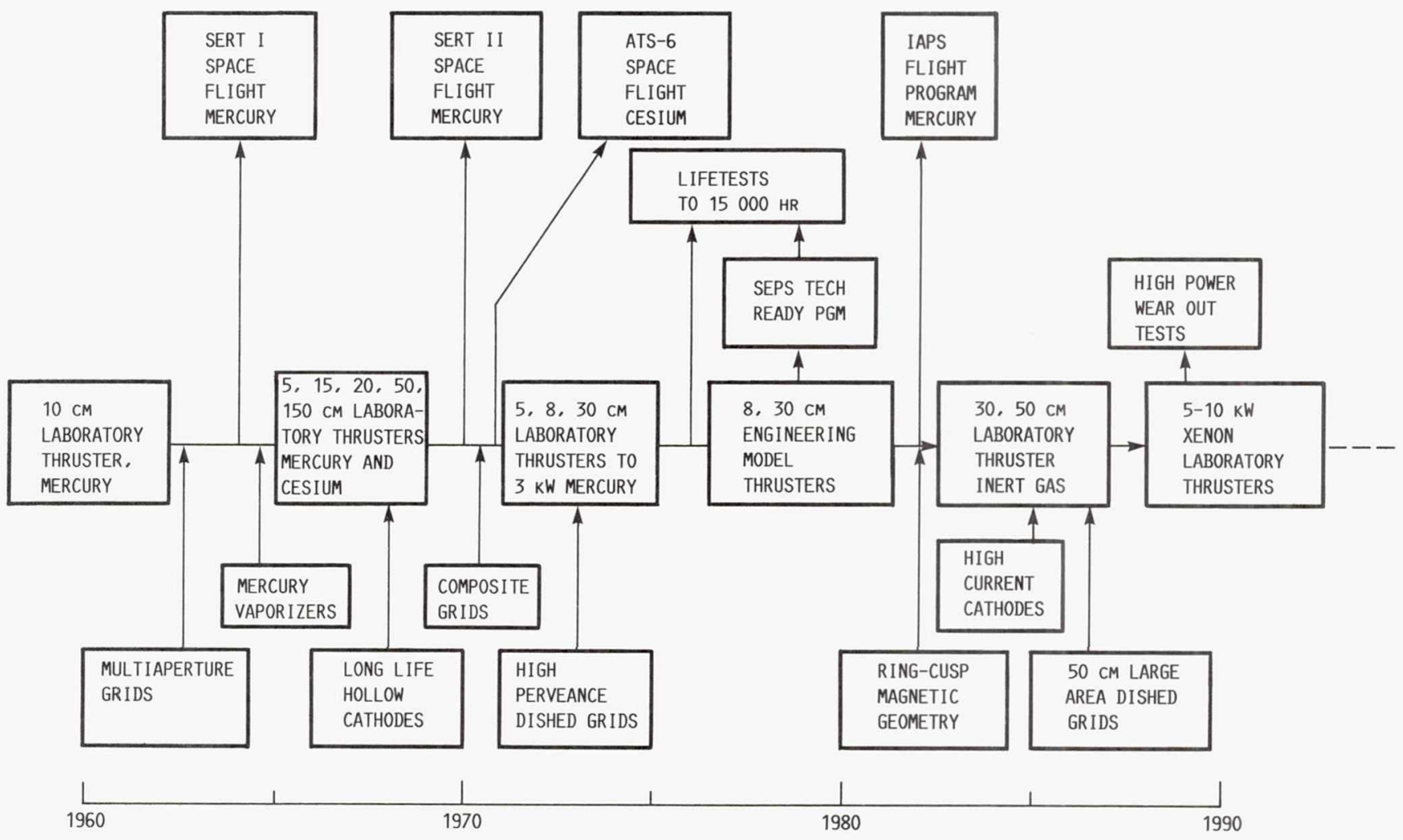

FIGURE 3. - HISTORY OF NASA ELECTRON BOMBARDMENT ION THRUSTER RESEARCH. 


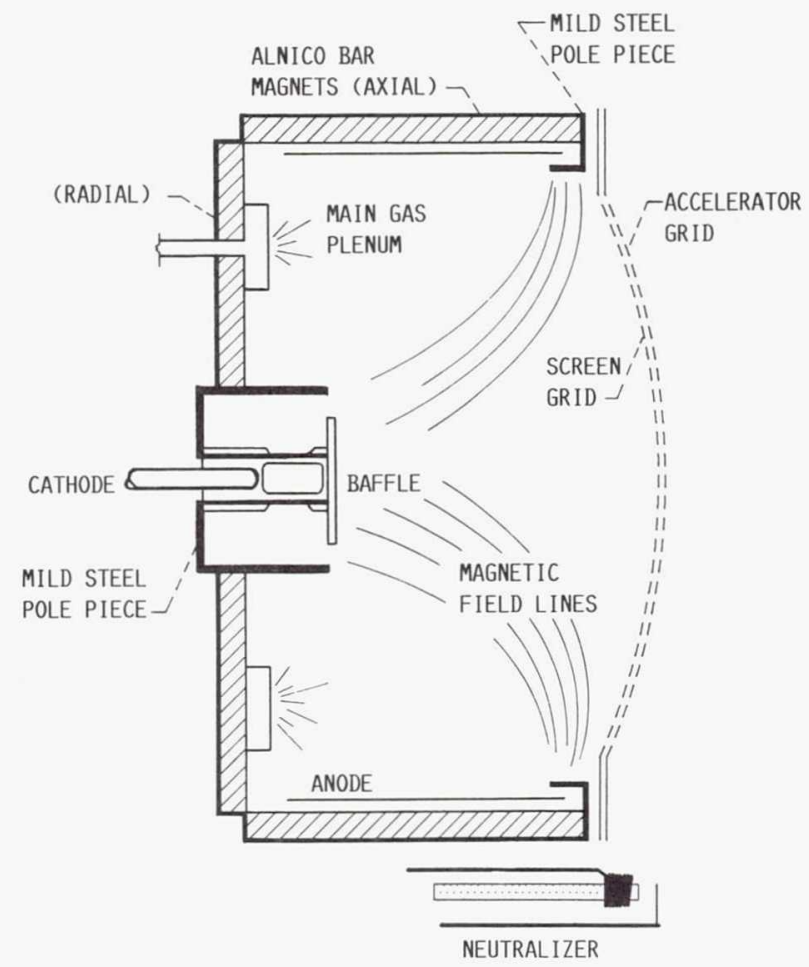

(a) TYPICAL SCHEMATIC.

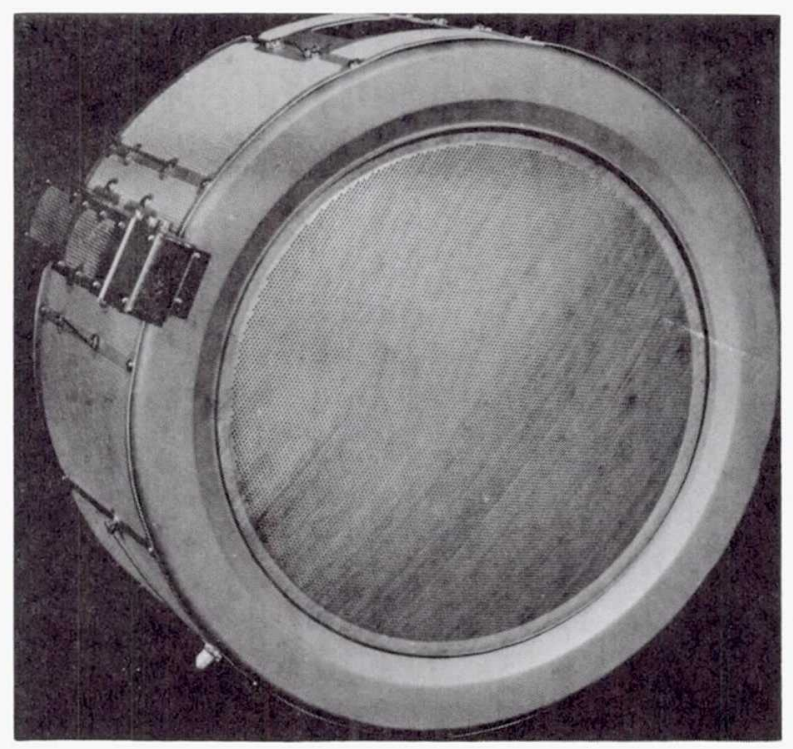

(b) SEPS THRUSTER.

FIGURE 4. - DIVERGENT MAGNETIC FIELD ION THRUSTER. 


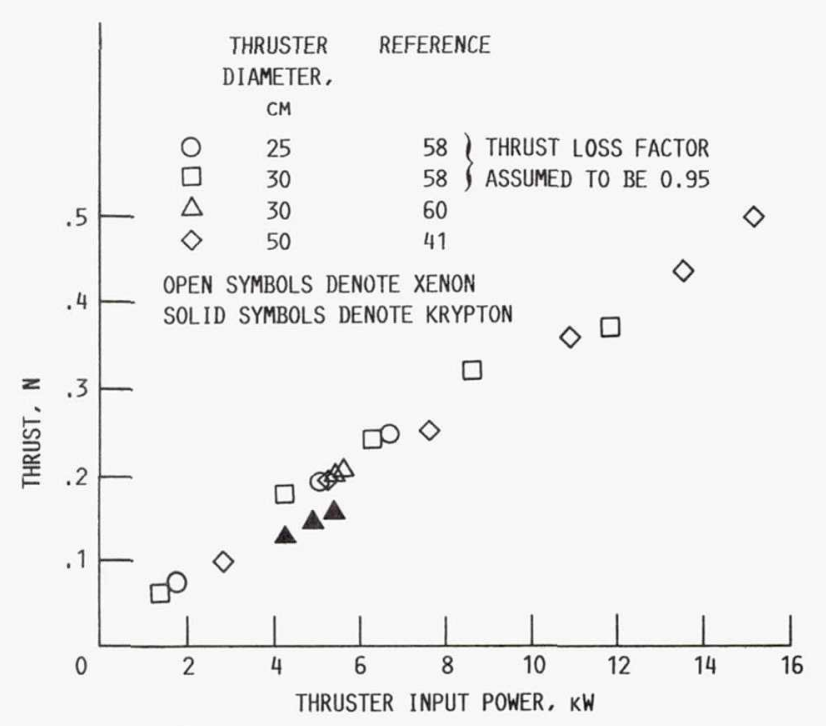

FIGURE 5. - THRUST AS A FUNCTION OF THRUSTER INPUT POWER.

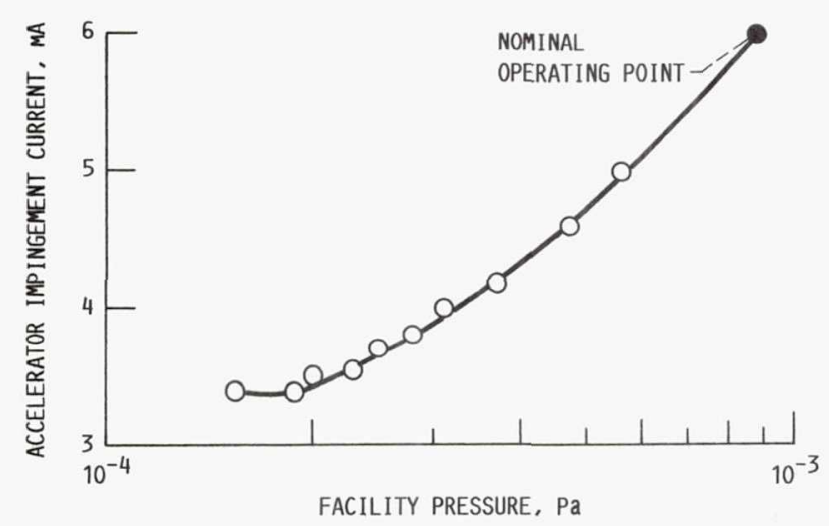

FIGURE 7. - ACCELERATOR IMPINGEMENT CURRENT AS A FUNCTION OF FACILITY PRESSURE (CONSTANT BEAM CURRENT OF $0.7 \mathrm{~A}$, TWO-GRID 25 CM THRUSTER).

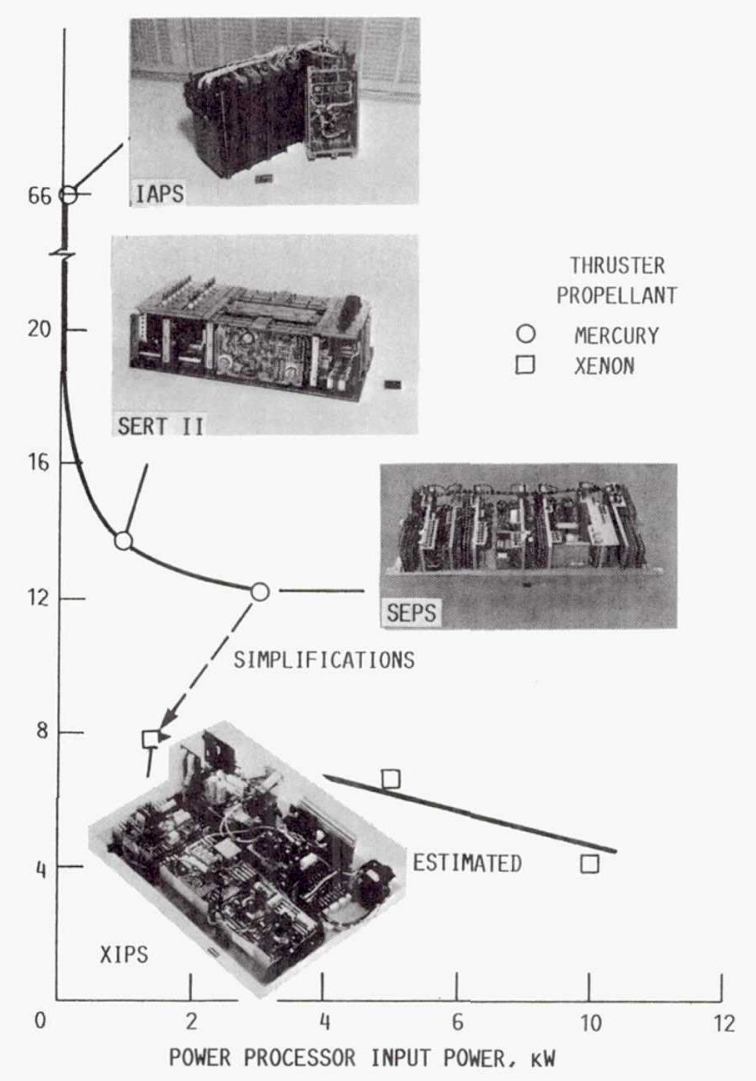

FIGURE 8. - POWER PROCESSOR SPECIFIC MASS AS A FUNCTION OF INPUT POWER. 


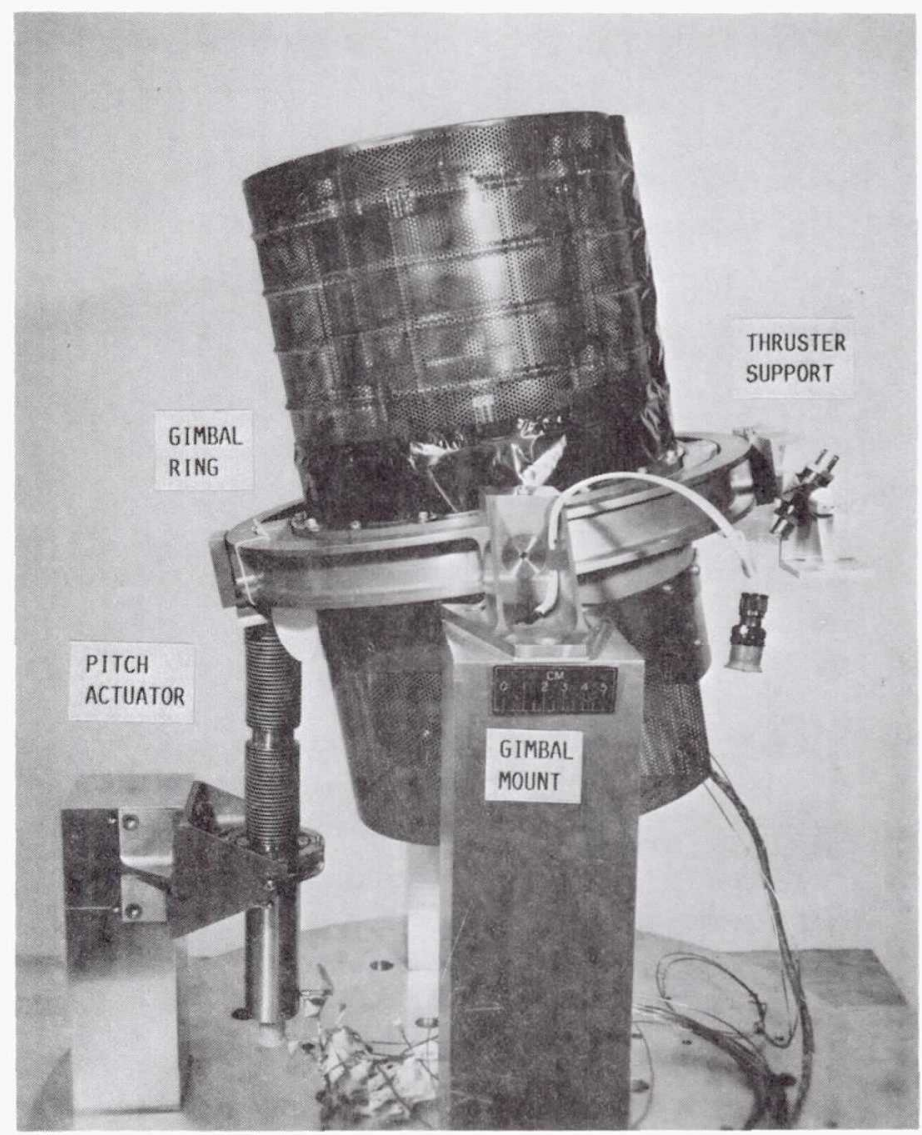

(a) SERT II THRUSTER.

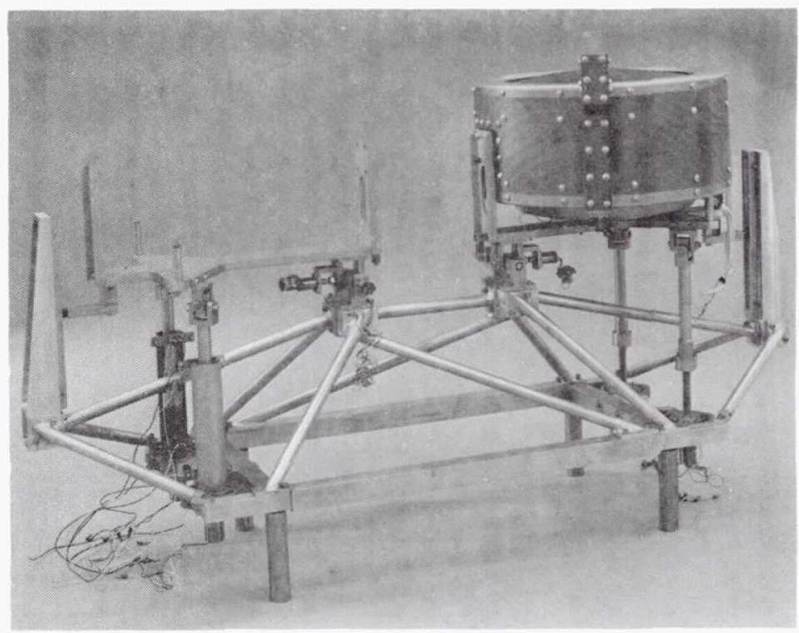

(b) SEPS THRUSTER.

FIGURE 9. - GIMBAL SYSTEMS.

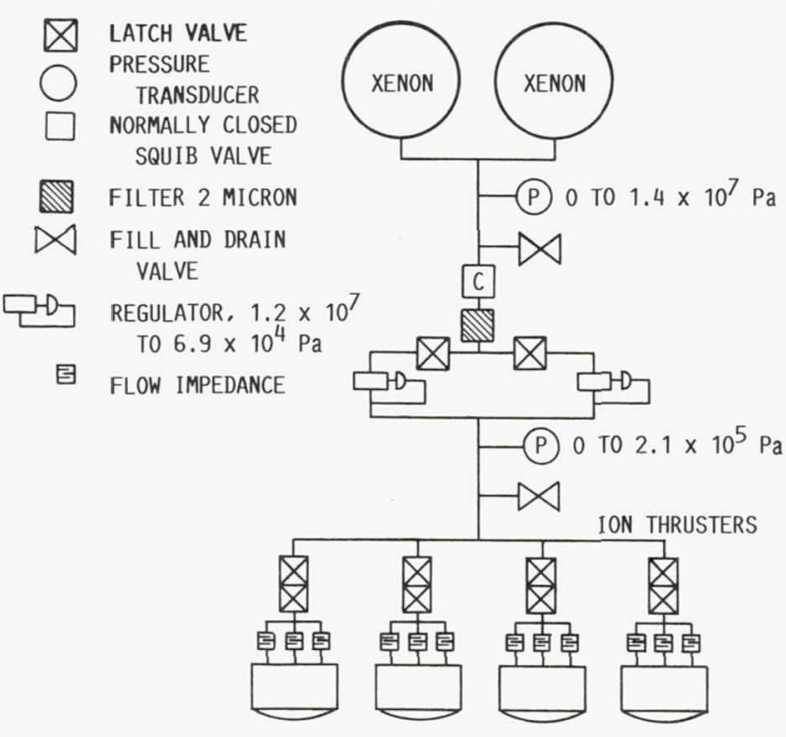

FIGURE 10. - PROPELLANT TANKAGE AND DISTRIBUTION SYSTEM (REF. 26). 


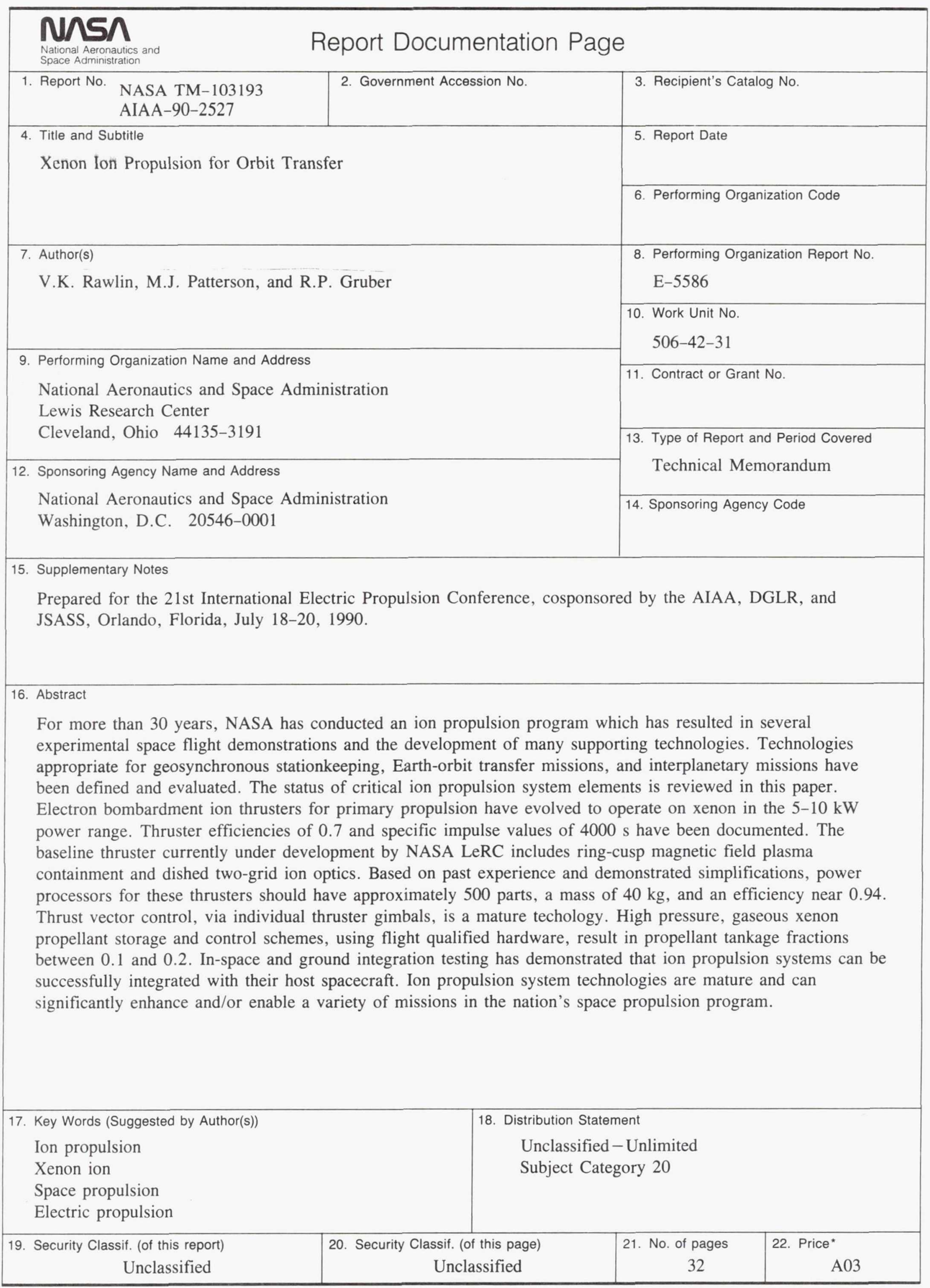

